\title{
XXXI. Rays of positive electricity
}

\section{J.J. Thomson M.A. F.R.S.}

To cite this article: J.J. Thomson M.A. F.R.S. (1907) XXXI. Rays of positive electricity, Philosophical Magazine Series 6, 14:81, 359-364, DOI: 10.1080/14786440709463691

To link to this article: http://dx.doi.org/10.1080/14786440709463691

$$
\text { 册 Published online: } 16 \text { Apr } 2009 .
$$

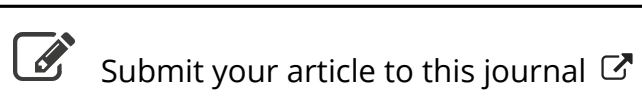

\footnotetext{
Џlll Article views: 13
}

Q View related articles $\square$

Citing articles: 1 View citing articles 4 
1/3400 de millimètre. Un grand nombre de stries avaient traversé la couche d'argent de manière à donner naissance à autant de fentes d'une ténuité extrême. Ces lignes lumineuses étant observées, à l'aide d'un analyseur, au microscopo éclairé par la lumière solaire, ont présenté les phénomènes de polarisation déjà décrits, c'est-à-dire qu'un grand nombre d'entre elles étaient polarisée dans un plan perpendiculairo à leur longueur.

"Mais en observant avec plus d'attention les moins lumineuses de toutes ces lignes, c'est-à-dire celles qui devaient être les plus fines, on en a trouvé un certain nombre qui présentaient un phénomène de sens opposé, c'est-à-dire qu'elles étaient polarisées dans un plan parallèle à leur longueur, les unes totalement, les autres partiellement; cet effet étant accompagné de phénomènes de coloration semblables à ceux qui ont été signalés dans les lignes qui donnent la polarisation perpendiculaire."

The passage of electric or luminous waves through a fine slit in a thin perfectly conducting screen was considered by me in a memoir published ten years ago*. If the electric vector is parallel to the length of the slit, the amplitude of the transmitted vibration is proportional to the square of the width of the slit; but if the electric vector is perpendicular to the length of the slit, the transmitted vibration involves the width only as a logarithm-see equation (46) - much as in equation (21) of the present paper. If the incident vibration be unpolarized and the slit be very fine, the latter component preponderates in the transmitted waves, viz. the direction of polarization is parallel to the length of the slit, in accordance with Fizeau's observations upon light transmitted by apertures of minimum width.

Terling Place, Witham, July 1907.

XXXI. Rays of Positive Electricity.

By J. J. Thomson, M.A., F.R.S.†

TN a paper on the rays of positive electricity (Phil. Mag. May 1907) I showed that these rays in gases at very low pressures consisted mainly of streams of two kinds of positively charged particles, the value of $e / m$ for one stream being $10^{4}$ and for the other $5 \times 10^{3}$. As these are respectively the values of $e / m$ for charged atoms and molecules of hydrogen, it might be thought that the rays of positive electricicy were dependent on the presence of hydrogen in the discharge-tube. The results described in the previous paper were not, as I

* Phil. Mag. xliii. p. 259 (1897); 'Scientific Papers,' iv. p. 283. See also Phil. Mag. July 1907.

$\dagger$ Communicated by the Author. 
pointed out, in accordance with that view; and direct measurements have shown that the intensity of the rays in different gases is not connected with the amount of hydrogen in the tube. The method adopted was to measure photometrically the brightness of the phosphorescent patches produced by the rays with the aforesaid values of $e / m$ on a scraen covered with willemite. This was done as follows:Light of the same colour as the willemite phosphorescence was produced by sending the light from an incandescent lamp through a weak solution of fluorescine: with a little care it is easy to get a solution in which the fluorescence produced by white light is a very good match for the fluorescence produced by the positive rays on the willemite. A small glass tube A (fig. 1) containing such a solution was

Fig. 1.

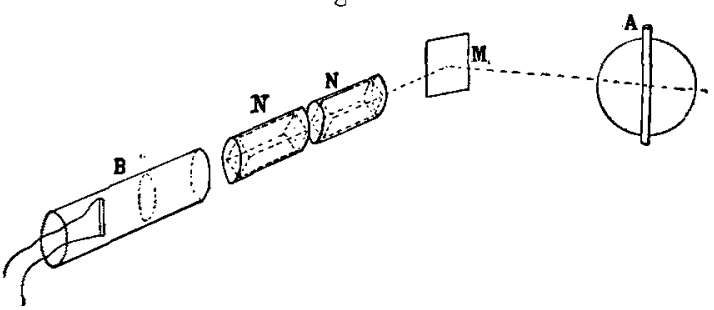

placed against the willemite screen on which the rays impinged; the tube was illuminated by light whose intensity was adjusted in the following way. A Nernst lamp was placed at the end of a long tube B; the light from this, after passing through a lens, went through two Nicol prisms $N, N$ placed in graduated holders : after passing through the nicols the light was reflected parallel to the screen from a mirror $M$ and produced in the fluorescine a phosphorescent patch side by side with that produced by the rays on the willemite. When the planes of the two nicols were at right angles to each other, no light got through; when the planes were parallel so much light got through that the phosphorescence of the fluorescine was greater than that of the willemite. By rotating the nicols the angle between them could be adjusted so that the light passing through made the phosphorescence of the fluorescine equal to that of the willemite. The angle between the planes of the nicols in this position gave a measure of the intensity of the light from the fluorescine, and therefore of that produced by the positive rays.

The current passing through the discharge-tube was measured by a galvanometer. The brightness of the positive rays depends upon a good many things besides the current through the tube; but the current is one of the important factors, and 
it would not be legitimate to compare the intensity of the phosphorescence on the willemite if the currents were very different.

The procedure was as follows:-The discharge-tube originally full of air was exhausted, and measurements of the brightness of the patch of phosphorescence produced by the rays for which $e / m=10^{4}$ were made for measured values of the current through the tube: the tube was then further exbausted until the discharge only passed with great difficulty. Sealed on to the discharge-tube was another tube containing potassium permanganate: this was connected with the discharge-tube by a long spiral tube dipping into a reservoir which was kept filled day and night with liquid air, so as to prevent any water-vapour reaching the discharge-tube. A similar spiral in liquid air was placed between the discharge-tube and the pump. The permianganate was heated and the tube filled with oxygen ; this was pumped out and the brightness of the phosphorescence measured; the exhaustion was then carried to the stage when the discharge only passed with difficulty; the permanganate was again heated and the process repeated. This procedure was kept up for six days, the total number of fillings with oxygen being about 70. The discharge from a large induction-coil was kept running through the tube for about 6 hours each day, being only stopped during the short intervals when the exhaustion had been carried so far that the discharge passed with difficulty, and there was a danger of breaking the tube by sparking through the glass. Measurements of the brightness of the phosphorescence with given currents through the tube were made from time to time, but there was no indication of any diminution. At the end of the run the tube was opened and hydrogen let in, when again with the same current the intensity of the phosphorescent patch was the same as before. The hydrogen was pumped out and helium admitted, and in this case the phosphorescence seemed a little brighter than before, though the difference was not considerable. There is thus no indication that the positive rays are dependent upon the presence of hydrogen in the tube.

Positive rays are very widely distributed through the tube. The positive rays are to be found throughout the tube, and not merely passing through apertures in the cathode and in the layer of luminosity adjacent to it. The positive rays which were used in the preceding experiment as well as those used in all the experiments described in the previous paper, were rays which had passed through an aperture in the cathode. I have found, however, that positive rays are to be found in all parts of the tube which have an uninterrupted view of the ordinary "Canalstrahlen" or of that luminous patch next 
the cathode of which the Canalstrahlen are the prolongations. The first place in which they were found is right in front of the cathode. The discharge-tube is represented in fig. 2. A perforated plug was placed at the entrance of the tube A,

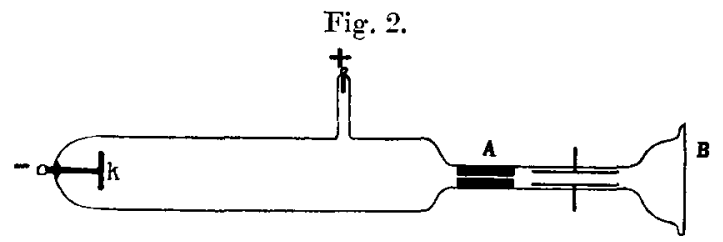

and at the end of this tube there was a willemite screen B; the tube passed between the poles of a powerful electromagnet of the $\mathrm{Du}$ Bois type and contained two parallel plates, which when connected with a large battery of small storagecells had a strong electric field between them. When $k$ was cathode, the tube was flooded with ordinary cathode rays, but these could easily be turned to one side by a small permanent magnet: when this was done there still remained a bundle of rays passing through the aperture which were not appreciably deflected by the weak magnetic field, but which suffered appreciable deflexion by strong magnetic and electric fields. The direction of the deflexion showed that they consisted of positively charged particles; the magnitudes of the deflexions were comparable with those of the rays which pass through apertures in the cathode; but even rough measurements were sufficient to show that the velocity of these particles in front of the cathode was less than that of the particles which had traversed the cathode. Villard (Comptes Rendus, vol. vii. p. 674) has described a similar experiment and obtained the same results. The luminosity produced on the screen in this experiment, though quite appreciable, was much less than that produced by the ordinary Canalstrahlen, and was rather too faint to allow of very accurate measurements of $e / m$ and $v$. I have deferred making these measurements in the hope of improving the apparatus so as to get much brighter phosphorescence. Along with the rays which were positively deflected, there were others which were not deflected by the strongest fields I could apply; and, as in the case of the rays coming through the cathode, there were some rays which were deflected in the negative direction, and which consisted of particles having a negative charge and a mass much greater than that of a corpuscle. The existence of the positive rays in front of the catbode and travelling away from it, might be explained by a kind of reflexion of those travelling towards the cathode: we might suppose that some of these, when close to the cathode, 
got negatively charged by the adhesion of corpuscles. The strong electric field near the cathode would shoot these away from it, and they might in their journey through the tube lose by collision with the gas not only the corpuscles they had acquired, but also an additional one, and thus become positively charged. Another way of explaining these rays is to regard the gas traversed by the positive particles moving rapidly towards the cathode as being thrown into a condition analogous to that of a radioactive substance and shooting out with great velocity positively electrified particles (corresponding to the $\alpha$ particles), as well as corpuscles (corresponding to the $\beta$ particles). If this were the case, the positive particles might be expected to be shot out in all directions; while on the other view they would tend to follow the lines of force in the tube and be mainly right in front of the cathode.

To test this point the following arrangement was used. The cathode $k$ (fig. 3) was an aluminium disk with a hole at the centre through which the Canalstrahlen passed; after passing through the tube these rays fell

Fig. 3. on a copper plate $c$ rigidly attached by an arm to the cathode but insulated from it. The cathode floated on the mercury in a barometercolumn, and by raising or lowering the level of the mercury different regions near the cathode could be brought opposite to the end of the side-tube T; at the mouth of this tube there was an insulated metal plug with a hole bored through it. The tube passed between the poles of a powerful electromagnet of the Du Bois type; a willemite screen was fastened to the end of the tube: the anode was at A. Starting with the cathode in such a position that the axis of the hole in the plug passed through $l$, the luminosity produced by the positive rays above the cathode, it was found that rays of positive electricity passed down the side-tube; gradually raising the cathode, these rays remained until the plane of the cathode just got above the opening in the plug, when they disappeared. On raising the cathode still 
further, the rays were absent until the bottom $m$ of the tube in the cathode came opposite the opening, and the axis of the opening therefore passed through the Canalstrahlen, when they reappeared; they became brightest of all when this axis passed through the part of the plate $\mathrm{C}$ struck by the Canalstrablen passing through the tube. The fact that the rays were not visible when the slit was opposite the tube indicates that the rays are not mainly due to the metal plug getting charged negatively by the cathode rays and acting as a secondary cathode. W We see from this that particles of positive electricity are shot off in all directions from the gas traversed by the Canalstrahlen. The results just described were obtained when the tube was filled with air or with hydrogen; other gases have not yet been tried. The intensity of rays emitted sideways is small compared with the intensity of those observed in front of the cathode in the preceding experiment, so that there must be considerable reflexion of the direct rays. This view is also supported by the fact that the velocity of these rays is not constant, but increases with the velocity of the Canalstrahlen.

I wish to thank Mr. Everett for the assistance he has given me in these experiments.

Cavendish Laboratory, Aug. 6, 1907.

XXXII. The Scattering of Sound by Spheroids and Disks. By J. W. Nrcholson, D.Sc., B.A., Isaac Newton Student in the University of Cambridge*.

W HEN a plane train of sound wares falls on a small spheroid or disk, formulæe expressing the scattering effect have been given by Lord Rayleigh $\uparrow$, who employs a method based on an analogy with potential theory. The formulæ are first approximations, holding only when the ratio of linear dimension to wave-length is very small. The deduction of more accurate expressions requires the use of harmonic analysis. This analysis has been given by Lord Rayleigh $\ddagger$ for the case of the sphere, but the further examination of the problem of the obstructing spheroid or disk does not appear to have been carried out. The object of this paper is to develop a suitable harmonic analysis, and to

* Communicated by the Author.

† Phil. Mag. Jan. 1897; Scientific Papers, iv. p. 305.

$\ddagger$ 'Theory of Sound,' vol. ii. $\$ 334$. 